\title{
Projective aspects on cognitive performance: distortions in emotional perception correlate with personality
}

\author{
Fabiano Koich Miguel ${ }^{*}$ and Fernando Pessotto
}

\begin{abstract}
Several approaches in psychology converge with the concept that individual characteristics may interfere with the perception and interpretation of the world. We hypothesized that such phenomenon could be identified in instruments that were not only projective techniques. The research's goal was to study perceptive distortions in a cognitive test and their relations with personality instruments. Responses from 222 participants in the Computerized Test of Primary Emotions Perception (PEP) were rated in distortion scores, which related to perceiving emotions that were not present. We used Spearman correlations between these scores and the Rorschach Inkblot test, Dimensional Clinical Personality Inventory, and tasks of Verbal and Abstract Reasoning. Results showed that the distortions were not related to intellectual abilities. Distortions of joy were associated with greater interest in interpersonal contact; love with positive view of the interactions and need for attention; fear with concerns about aggressiveness and autonomy; sadness with lower perception of damaged objects; disgust with feelings of loneliness; and anger with criticism avoidance, distrust, feelings of loneliness, and aggressive behaviour. The results support the proposal that altered perception of reality is related to affective or personality characteristics.
\end{abstract}

Keywords: Psychological assessment, Emotional intelligence, Facial expressions, Projective techniques

\section{Background}

In the psychological assessment of personality, two major groups of instruments are often identified: self-report inventories and projective techniques. While the format of the first group tends to be reasonably similar, the second varies greatly. There are techniques that consist in saying what inkblots look like (e.g., Rorschach, Zulliger, Holtzman), telling stories from pictures (e.g., Thematic Apperception Test and its derivatives), making drawings (e.g., Draw a Person, House-Tree-Person, Wartegg), among many others. Nevertheless, they all share the proposition of offering a task for the subject to perform and then evaluate affective, motivational, cognitive, and even pathological aspects (Fensterseifer and Werlang 2008).

Psychoanalysis is traditionally recognized as the theory that underlies projective tests, although, in fact, others also have made contributions. Below is a brief review of classical theories that regard this class of instruments.

\footnotetext{
* Correspondence: fabiano@avalpsi.com.br

Universidade Estadual de Londrina, Londrina, Brazil
}

\section{Psychological theories of projective tests}

For psychoanalysis, the ego uses defence mechanisms, which are strategies to transform drives into suitable content for the environment. One of those mechanisms is projection. In a letter from 1895, Freud (1950/2006) proposed the concept whilst studying paranoia, suggesting that projection was the attribution to the outside world of an internal content that was incompatible with the ego. That way, an inner perception would be recognized by consciousness as external. In later writings, Freud (1913/2006) developed the idea that the projection takes place not only in conflict situations, but it would also be a healthy personality mechanism, changing the perception that individuals have of the world, based on their affects.

Based on the principle of projection, Frank (1939) proposed that the personality, when introduced to unstructured, ambiguous stimuli that lacked intrinsic meaning, would have a tendency to organize itself to assign a meaning to that. The author then considered that the personality assessment techniques available at the time - 
Rorschach inkblots, Thematic Apperception Test, among others - would start this process, allowing aspects of the individual's private world to be revealed like an $\mathrm{x}$-ray, thus, creating the term "projective methods".

Beyond psychoanalysis and derived practices, other theoretical approaches have considered regarding the phenomenon of having a personally meaningful performance on unstructured stimuli. In radical behavioural analysis, Skinner (1936) developed an assessment tool based on the theoretical assumption that the presentation of a stimulus tends to elicit a response that is similar to it. The behaviourist created a phonograph that repeatedly reproduced meaningless syllables recorded on a disc he titled Verbal Summator. Subjects were instructed to listen to the recording and to report as soon as they identified something that made sense to them. The reported word or phrase, of course, was not truly present in the recording. Because such verbal responses were not evoked by any real stimuli at that moment, the author considered that, by approximation, the test would elicit the strongest responses from the subject.

Although further studies pointed to the possibility of differentiating between psychiatric patients (for a review, see Rutherford 2003), with time, the complex machinery and redundancy compared to other tests eventually lessened interest in the Verbal Summator, causing it to virtually disappear by the end of the 1950's. Nevertheless, Skinner (1936, 1953/2003) still listed the advantages of such an instrument, considering that projective tests create a laboratory situation, enabling control over stimuli in the observation of behaviour and facilitating the emergence of behaviours that are not known by the subject, especially the verbal ones.

Cattell (1951/1978), who furthered the psychometric approach to psychological phenomena, proposed new classifications that represent forms of personality assessment. Within the objective test group, in which an artificial situation is created to observe the subject's behaviour, the author created the category of distortion or bad perception tests, which measure an unusual perception and a particular meaning of a real, objective fact that included projective techniques.

Since the perceptual distortions would not be influenced by intellectual capacities, Cattell (1951/1978) considered that the performance would then be a reflection of the reproduction (memory) of previous emotional experiences. To explain the occurrence of this phenomenon, the author proposed that internal perceptions alter interpretation of reality. In this sense, people that see themselves as incapable and worthless would see other people as distant and disinterested, justifying their own depression.

In the perspective of Gestalt psychology, events are experienced from the organization of the perceived stimuli, overcoming a vision of simple summation of latent traits and assigning a particular meaning to each stimulus presented (Koffka 1935/1975; Köhler 1947/1968). In this respect, the individual's particular way of acting consists of a series of dynamic characteristics, and from them, external stimuli are organized according to experience. Thus, experiences are characterized by an individual structure.

Individuals perceive stimuli in a meaningful perspective of their own, featuring their own way of perceiving, feeling, associating and acting beyond the presented stimulus, aggregating experiences and memories. Therefore, their interaction with the stimulus, including psychological tests, takes place according to their daily interaction in other situations, and the properties of parts of the stimulus depend on their relationship with the whole (i.e., the place, the meaning, and the function that it has in relation to the whole) as they are perceived by the individual (Crisi 2007; Freitas 1993; Kinget 1952).

In the field of neuropsychology, it is possible to find projective techniques being recommended, especially as ways of evaluating neurological trauma (Gabowitz et al. 2008; Spreen and Strauss 1998) due to their ability to measure perceptual organization, processing and stimuli integration (Acklin \& Wu-Holt, 1996; Lezak et al. 2004). Although not yet numerous, studies often use Rorschach's Inkblots Method to assess phenomena, such as mirror neuron activation during the production of movement responses (Porcelli et al. 2013), the role of amygdala as emotional interference during the process of perceiving and producing unusual frequency responses (Asari et al. 2010), Rorschach variables associated with Alzheimer's disease (Perry et al. 1996), among others.

According to Acklin (1994), the Rorschach method can be used by both neuropsychology and cognitive psychology by focusing on the response process. Information processing is understood as a cognitions sequence between stimulus and response that would work through behaviour selection, processing, and management. When one observes a Rorschach inkblot, a network of schemes is activated by combining current context and past experiences stored in long-term memory - or, more specifically, in episodic memory, which contains autobiographical information. Activated schemes are then managed by control processes that select and censor content (representations of ideas and feelings) to adapt to the characteristics of the stimulus (Acklin 1994; Acklin and Wu-Holt 1996). Although the authors only suggest the use of episodic memory, it is likely that semantic memory also influences the alterations of perception. Semantic memory is understood as the personal knowledge of facts and concepts, and is the basis of human activities that require use of symbols and their meanings, understanding of reality, and relationships between ideas (Binder and Desai 2011; Budson and Price 2007). 


\section{Considerations regarding alteration of perception in psychological tests}

Considering what was presented, it is possible to understand that there is a convergence in literature pertaining to the assertion that individual emotional aspects can influence the perception or interpretation of the world, and such phenomenon can be detected through performance on projective tests. However, as perception is a psychological activity that happens not only in those tests, we hypothesize that performance on other instruments would also be influenced by personality traits, and such influence can be measured.

Internationally, research has been conducted in this regard. In one study of patients with eating disorders (Joos et al. 2009), pictures of the International Affective Picture System (IAPS) were presented to 19 patients with bulimia nervosa, 15 with anorexia nervosa and 25 controls, and participants were asked to observe each image and to report on a scale the emotion they were feeling. The results showed that, when observing aggressive images, the group with anorexia reported feeling more afraid than the other groups, which the authors considered a reflection of those patients' typical avoidance of conflict.

In a study with 46 obsessive compulsive disorder patients compared with 23 controls, beyond the greater sense of social responsibility that is already known to the disorder, Moritz et al. (2011) found stronger latent (i.e., unexpressed) traits of aggression and distrust in the first group. These characteristics were identified in self-report questionnaires with items regarding desire to attack strangers on the street or lack of confidence in close people. For the authors, the expression of aggressiveness is contained by a high moral sense and then transformed into a perception of the world as dangerous and harmful.

In Brazil, intelligence tasks such as the Wechsler scales (Wechsler 2013) and the G-36 (Boccalandro 2003) provide instructions to score and classify errors and distortions occurring in performance. However, such distortions are presented only as cognitive data; there are no studies linking them to aspects of personality.

\section{Goal and hypotheses of the study}

We identified a gap in the research regarding the influence of personality characteristics on performance in instruments beyond projective tests. The present study aimed to analyse the distortions of perception on a cognitive ability test through correlation with personality instruments as well as other cognitive abilities. We chose a test of emotional perception, which assesses the ability to identify the emotions expressed in videos of people. Distortion was understood as the perception of something not present in the original stimulus (i.e., perceiving an emotional expression on a person's face that is not actually present). According to the literature review, we hypothesized that distortions would not be related to cognitive performance, but with the particular forms that the subjects perceive in themselves and the world. The following hypotheses were designed to be compatible with the variables of the tests we used and the meaning of each emotion, according to the literature in the field (Ekman 2003; Niedenthal et al. 2006; Plutchik 2002; Strongman 2003).

Hypothesis 1. Distortion of joy (gain of something socially valued) will correlate with increased interest in human contact.

Hypotheses 2 and 3. Distortion of love (feeling of being accepted) will correlate with more positive views of interactions and a greater need to receive attention from others.

Hypotheses 4, 5, and 6. Distortion of fear (attention to threatening stimulus) will correlate with higher frequencies of oppositional behaviours and attention to aggressive movements and contents.

Hypothesis 7. Distortion of sadness (feelings of losing something and negative thoughts) will correlate with greater perceptions of damaged, spoiled or harmed objects.

Hypothesis 8, 9, and 10. Distortion of disgust (attention to aversive stimuli) will correlate with increased need for contact due to feelings of loneliness, suspicion, and concern about intentions of others, and belief that others can humiliate and criticize.

Hypotheses 11, 12, 13, 14, 15, 16, and 17. Distortion of anger (attention to aggressive and hostile stimuli) will correlate with lower frequencies of exploratory behaviour, greater need for contact and feelings of loneliness, attention to aggressive movements and content, disregard and aggressive behaviours toward others, suspicion and concern about intentions of others, and belief that others can humiliate and criticize.

\section{Method \\ Participants}

The 222 participants were drawn from a database of previous administrations. The average age was 22.83 $(\mathrm{SD}=6.87)$ with a minimum of 18 and maximum of 27 years, $58.8 \%$ female, $13.9 \%$ male and $27.2 \%$ that did not inform. Participants were undergraduates or graduate students.

\section{Instruments}

Computerized test of Primary Emotions Perception (PEP)

The PEP is an online test that presents 38 videos of people's faces expressing emotions, and the first three are used as examples of the task. Participants watched each video and selected which emotion or emotions were present in that expression from a list of eight: joy, 
love, fear, surprise, sadness, disgust, anger, and curiosity. Recent research has shown evidence of construct validity, that is, adequate factor structure for the theoretical assumptions, moderate correlations with other types of intelligence (abstract reasoning, $r=.36$; verbal reasoning, $r=.38$ ), and correlations close to null with self-reported personality traits (Miguel et al. 2013a, b; Miguel and Primi 2014).

For this research, new PEP scores were developed, which are the scores of distortion of emotional perception. For each of the eight emotions, when the participant identified its presence in the video, one point was added to the total amount of that emotion. Thus, we obtained eight final scores indicating the total amount of each emotion. At the end, we subtracted from each score the actual frequency of each emotion in the PEP. For example, a resulting score of -2 for anger indicates that the participant identified two expressions of anger less than what is truly present in the test; a score of five for anger indicates that the participant identified five more emotions of anger than what is present in the test.

The people presented in the videos were originally filmed watching multimedia stimuli on a computer, which facilitated expressions of surprise or curiosity. For this reason, these two emotions were not studied as distortion scores.

\section{Rorschach inkblot method}

The Rorschach method consists of ten cards with multicolored, symmetrical inkblots, administered in two phases: First, participants respond to what the blots look like and then a clarification is conducted regarding what gave that idea. After that, registered verbalizations are coded. Recently, researchers undertook an extensive review of the method's validity (Meyer et al. 2011; Mihura et al. 2013) that resulted in the R-PAS system of administration, codification, and interpretation used in this study. Test variables were selected according to their relevance to the analysis of this study (expressed in the hypotheses). The scores were standardized (mean $=100$ and standard deviation, 15).

\section{Dimensional Clinical Personality Inventory (IDCP)}

IDCP is a self-report inventory featuring 163 sentences that participants responded to using a Likert scale of 1 to 4 . The inventory evaluates 12 factors related to clinical conditions or personality disorders: Dependency, Aggressiveness (Agress.), Mood Instability, Eccentricity, Attention Seeking (Att.Seek.), Distrust, Grandiosity, Isolation, Criticism Avoidance (Crit.Av.), Self-Sacrifice, Conscientiousness, and Impulsiveness (Carvalho and Primi 2013).

\section{Abstract and Verbal Reasoning (RA and RV)}

To assess cognitive abilities, we used the RA and RV tasks, which are part of the Battery of Reasoning Tests (Primi and Almeida 2000). In RA, 28 items present two abstract geometric shapes, with the first transformed into the second (e.g., size, number of lines, etc.). The rule for transformation must be applied in a third figure to find the correct answer from five alternatives. In RV, 28 items follow the same structure, but it presents related words instead of geometric figures. In both tests, the first three items are used as examples.

\section{Procedure \\ Data collection}

Data used in this study were drawn from a research database, which was registered in SISNEP under the protocol CAAE 0159.0.268.000-10 and approved by the Research Ethics Committee of the State University of Londrina with protocol 191/2010.

Participants were invited, both personally and through social media, to participate in the research conducted at the State University of Londrina. After subjects signed the informed consent, the tests were administered. To avoid fatigue, the instruments were presented in alternation, that is, PEP was applied followed by a second test, alternating Rorschach, IDCP, RA and RV, in this sequence. Thus, the 222 participants answered the PEP and at least one of the other instruments: 55 answered the Rorschach, 57 the IDCP, 65 the RA, and 56 the RV.

\section{Data analysis}

To verify the hypotheses, the PEP was correlated with selected variables of both personality tests in addition to the reasoning tasks. Given the non-parametric nature of some variables, we used the Spearman correlation, considering a value of .05 or lower for statistical significance. The interpretations of the variables of the tests were conducted according to their respective literatures, aforementioned in the Instruments section.

\section{Results}

We initially performed descriptive statistics of the variables presented in Table 1. For tests RV, RA, and IDCP, it is possible to identify a wide distribution of scores, suggesting variability in the results. The same can be said about the Rorschach scores, which tended to be located around the mean of 100 and standard deviation close to 15 . The only exception was for the CT variable, whose average was 115 , indicating that the participants of this study tended to have more card rotation behaviours than most people.

In relation to the PEP distortion variables, it is possible to recognize that the widest range of scores were of joy and fear, with a balanced distribution of distortions for 
Table 1 Descriptive statistics of the variables

\begin{tabular}{lllll}
\hline Variable & Median & SD & Minimum & Maximum \\
\hline Joy & -1 & 1.95 & -7 & 7 \\
Love & 0 & 1.80 & -2 & 5 \\
Fear & -2 & 1.75 & -5 & 5 \\
Sadness & 2 & 2.5 & -2 & 8 \\
Disgust & -4 & 1.68 & -7 & 1 \\
Anger & 0 & 1.71 & -3 & 6 \\
SumH & 106 & 14.63 & 71 & 131 \\
COP & 102 & 13.56 & 88 & 145 \\
AnyS & 102 & 13.47 & 73 & 123 \\
AGM & 93 & 14.50 & 93 & 146 \\
AGC & 94 & 12.88 & 74 & 132 \\
MOR & 100 & 16.07 & 86 & 143 \\
T & 91 & 13.29 & 91 & 140 \\
CT & 115 & 13.86 & 86 & 136 \\
Agress. & 1.48 & 0.42 & 1.00 & 3.56 \\
Att.Seek. & 2.13 & 0.57 & 1.19 & 3.56 \\
Distrust & 2.23 & 0.57 & 1.15 & 3.85 \\
Crit.Av. & 1.57 & 0.63 & 1.00 & 4.00 \\
RV & 19 & 3.05 & 10 & 25 \\
RA & 20 & 3.25 & 12 & 24 \\
\hline
\end{tabular}

both presence and absence of the emotion. Love and anger had less symmetric distributions, with greater tendency to distort the presence of emotion, although absence was represented as well. However, disgust got few scores for the presence of distortion, and the maximum score was one (which indicated greater presence), concentrating in the absence of distortion. In contrast, sadness obtained many scores for the presence of distortion, but few indicating absence, and generated a minimum score of -2 .

To verify the relationship of the distortion scores with the other tests, Spearman correlations were conducted. Table 2 shows the results.

Correlations of distortion scores with both reasoning tasks were low and not significant, demonstrating the lack of relationship between the constructs. As for the association between the distortions with Rorschach and IDCP, from the 17 initial hypotheses, 14 achieved statistical significance, suggesting an association existed between the scores.

\section{Discussion}

The absence of significant correlations between the distortion scores and the two reasoning tasks (RA and RV) suggests that there is no cognitive component permeating the distortion in the test, or, at least, its effect is statistically negligible, consistent with Cattell's proposal
Table 2 Spearman correlations between PEP distortions and Rorschach $(N=55), \operatorname{IDCP}(N=57), \mathrm{RA}(N=65)$, and RV $(N=56)$ variables

\begin{tabular}{|c|c|c|c|}
\hline Variables & Rho & Variables & Rho \\
\hline H1. joy $\times$ SumH & $.35^{* *}$ & joy $\times$ RA & -.15 \\
\hline $\mathrm{H}$ 2. love $\times$ COP & $.27^{*}$ & joy $\times R V$ & .16 \\
\hline H3. love x Att.Seek. & $.28^{*}$ & love $\times$ RA & .11 \\
\hline H4. fear x AnyS & $.50^{* * *}$ & love $\times$ RV & -.08 \\
\hline H5. fear x AGM & $.29^{*}$ & fear $\times \mathrm{RA}$ & -.08 \\
\hline H6. fear x AGC & .23 & fear $\times$ RV & .17 \\
\hline H7. sadness $\times$ MOR & $-.35^{* *}$ & sadness $\times$ RA & .11 \\
\hline H8. disgust $\times T$ & $.31^{*}$ & sadness $\times$ RV & -.05 \\
\hline H9. disgust $x$ Distrust & .01 & disgust $\times$ RA & .14 \\
\hline H10. disgust $\times$ Crit.Av. & .26 & disgust $\times$ RV & -.22 \\
\hline $\mathrm{H} 11$. anger $\times \mathrm{CT}$ & $-.37^{* *}$ & anger $\times \mathrm{RA}$ & .02 \\
\hline H12. anger $x T$ & $.52^{* * *}$ & anger $\times \mathrm{RV}$ & .03 \\
\hline H13. anger $\times$ AGM & $.30^{*}$ & & \\
\hline H14. anger $\times$ AGC & $.32^{*}$ & & \\
\hline H15. anger x Agress. & $.40^{* *}$ & & \\
\hline H16. anger $\times$ Distrust & $.33^{*}$ & & \\
\hline H17. anger $\times$ Crit.Av. & $.31^{*}$ & & \\
\hline
\end{tabular}

${ }^{*} p<.05 ;{ }^{* *} p<.01 ; * * * p<.001$

(1951/1978). Therefore, it is possible to consider the distortion of emotional expressions as a non-cognitive aspect that can be measured by the PEP.

According to the international literature that defines the psychological aspects related to emotional states and reactions (Ekman 2003; Niedenthal et al. 2006; Plutchik 2002; Strongman 2003), joy and love are understood as emotions that bring well-being and are usually associated with maintenance of interactions, although joy is more related to gain of valued resources in a greater number of interactions, while love is more related to intimacy, commitment, and care for others, that is, the quality of feeling accepted. This information could explain the relationship of the distortion of joy with SumH, suggesting greater interest in interpersonal experiences and exchanges. Accordingly, we also found relationships between distortion of love with COP and IDCP's Need for Attention factor. Participants that displayed greater need for being well-accepted, received, and cared for by others, viewed interactions positively and tended to perceive emotional expressions of love where they did not exist.

With regard to the distorted perception of fear in others, the results showed a strong association with answers using white space in Rorschach (AnyS), typically associated with individual effort and opposition. Although correlation tests do not allow causal inferences, an explanatory hypothesis can be suggested for this result. 
Probably, individuals seeking to show they are assertive or challenging can be perceived as differentiated or imposing figures. This would also explain the association with mentalization of activities and aggressive movements (AGM), but not aggressive objects (AGC). In this sense, there could be a personal interpretation that imposing and autonomous behaviours occur more aggressively, not through dangerous objects but the physical imposition, confirming the expression of fear of others when faced with such manifestations.

Regarding sadness, the initial hypothesis was that distortions are related to more frequent perceptions of objects in ruins, damaged or spoiled, captured by the code MOR, but the negative correlation indicated that the relationship took place in the opposite direction. Being MOR often understood as an indicator of selfesteem, the result suggests that the lower one's selfesteem, the lower the perception of sadness in others. Therefore, this is a case where the individual's emotional state is not identified equally in others, but in a reverse process. Possibly individuals who perceive themselves as damaged, worthless, and incapable that is, distorting the perception of themselves to a negative pole - also distort the perception of the world by decreasing its negative aspects. This operation could confirm an emotional state that justifies low selfesteem by seeing other people experiencing feelings of sadness less frequently than what is real.

Participants of this research produced few distortions for the presence of disgust. Although one of the proposed hypotheses was confirmed and another one reached a marginal level of statistical significance (Crit.Av., $p=.055$ ), still we suggest that this variable be analysed in another sample that presents a higher degree of distortion to understand what really is associated with distortion of disgust expressions.

Distortions of disgust and anger were associated with $\mathrm{T}$, indicating greater need for contact and the experience of feelings of loneliness. We raise the explanatory hypothesis that participants who perceive more expressions of disapproval in other people than are actually present avoid greater interpersonal contact to avoid criticism, which would generate the feeling of loneliness captured by $\mathrm{T}$. This relationship was not found in the distortion of disgust; however, as mentioned, this score needs to be reviewed in other studies.

We found significant correlations between perceiving more expressions of anger in others and having the belief that people might be criticizing or judging negatively (Crit.Av.) and between reporting greater distrust of other people's intentions and real motives (Distrust) and presenting fewer card turns in Rorschach $(\mathrm{CT})$, which is associated with a lower expression of creativity, flexibility, and even challenge. Integrating this information, we hypothesized that subjects who perceive more expressions of anger in people tend to attribute unreal critical judgments to them and then tend to avoid such criticism, moving away from contact or even presenting less autonomous behaviour to avoid conflict, resulting in distressing feelings of isolation and loneliness.

In the case of distortion of anger, unlike fear, there was a significant correlation with both AGM and AGC. These data suggest that identification or concerns with aggressive themes, both behaviours and objects, are associated with greater perception of aggressive expressions on other people. Agreeing with another initial hypothesis, we found an association between anger distortion and reports of violent behaviours and disregard for others (Agress.). These results suggest that the presence of aggressive thoughts in individuals manifests also in the form of distorted perceptions of anger in others.

The data regarding anger distortion, and especially love and fear distortions, support the proposal that an internal emotional perception is attributed to others. The results are in line with the studies and rationale reported by Joos et al. (2009); Moritz et al. (2011) in the sense that alterations of emotional perception is consonant with the individual's personality characteristics.

In scientific literature, there is sufficient evidence that the ability to perceive emotions is a type of cognition, related to but distinct from fluid intelligence (or abstract reasoning ability, measured in this study by RA), crystallized intelligence (or culturally acquired knowledge like verbal ability, partially measured by RV), or other types of reasoning (Miguel et al. 2013b; Peterson and Miller 2012; Schneider and McGrew 2012). However, distortions did not correlate with those two types of cognition; thus, other processes must be responsible for this perceptual organization and interpretation of reality. The various theories reviewed in the introduction mention significant emotional experiences stored in memory that could influence the perception of the present. Cognitive psychology and neuropsychology specify the concept of semantic memory as a neural network responsible for symbolic knowledge and for representations and meanings attributed to the world. This mind structure can even influence object recognition and social intelligence (Binder and Desai 2011; Budson and Price 2007). Further research should study the influence of these concepts, allowing a greater understanding of how the perception of stimuli in a psychological test (or even day-to-day) can be affected by life experiences.

It should be taken into consideration that the significant magnitudes of correlations ranged from .15 to .52 , with the majority in a range that is considered of mild association - around .30 (Cohen 1992; Meyer et al. 2001). Therefore, it is not possible to consider that the PEP distortion scores and the other tests are measuring 
exactly the same construct. However, those are not negligible associations. Rather, the shared variance suggests a common psychological process behind performance on the instruments: the quality of responses in Rorschach, the reporting of personality characteristics in IDCP, and the distortion of emotions in PEP. This psychological process seems to encompass more than just perception, but a perception that is altered by the individual's affective characteristics, consistent with the proposals found in the various theories reviewed in the Background.

\section{Conclusion}

Agreeing with the Campos's suggestion (2013), we found data on perception distortion was due to emotional characteristics using a test that was not designed to be projective, but to measure a cognitive ability (emotional perception). The distortions were consistent with personality traits measured by other instruments in the sense that personal characteristics appear to influence the interpretation of the world.

In addition, starting from what was stated in the introduction, the results have also made clear that this is not an exclusive phenomenon of one theoretical approach, but it can be interpreted and considered by several approaches. In the same way, other authors have suggested new terminology for projective methods, such as selfexpression or performance techniques (Meyer and Kurtz 2006; Miguel 2014; Villemor-Amaral 2014), to avoid biased use and to better describe the phenomenon. Along with this, we can see not only the possibility but the need to increase the amount of research by such approaches as cognitive, behavioural, and Gestalt psychology and neuropsychology regarding this class of instruments, accumulating new scientific evidence in Psychology.

A final consideration concerns the construct that psychological tests purport to measure. Although in Psychology we consider that individuals work with completely integrated psychological characteristics, most of the instruments focus on a specific aspect, especially those aimed at evaluating cognitive abilities. For example, there are tests that specifically measure concentrated attention, numerical reasoning, short-term memory, etc. We understand that there is a very good reason behind this specialization of the instruments, which is to identify individual capabilities or difficulties with greater precision. However, as suggested in the results of this study and as presented in the literature review, affective aspects can influence cognitive performance. Traditionally, these influences are seen in tests as measurement errors or situational influences that alter performance. To ignore the process behind these measurement errors may result in losing information about the functioning of individuals and their perceptions of the world.
As limits of research, we consider that the emergence of the perception distortion phenomenon may be due to the very format of the PEP, which features videos of people and proposes to measure emotional perception, a cognitive ability often used in social interactions where aspects of personality usually arise and interfere. More academic cognitive performances, such as numeric or spatial reasoning, may be less subject to interferences, as found in this study. Therefore, we recommend that other studies also evaluate the errors in these types of tests and compare them to personality traits so that more and more Psychology understands the interaction of these constructs.

\section{Competing interests}

The authors declare that they have no competing interests.

\section{Authors' contributions}

FKM carried out the psychological analyses, and participated in the manuscript. FP participated in the manuscript. Both authors read and approved the final manuscript.

Received: 8 March 2016 Accepted: 7 April 2016

Published online: 18 April 2016

\section{References}

Acklin MW. Some contributions of cognitive science to the Rorschach test. Rorschachiana. 1994;19(1):129-45. doi:10.1027/1192-5604.19.1.129.

Acklin MW, Wu-Holt P. Contributions of cognitive science to the Rorschach technique: cognitive and neuropsychological correlates of the response process. J Pers Assess. 1996;67(1):169-78. doi:10.1207/s15327752jpa6701_13.

Asari T, Konishi S, Jimura K, Chikazoe J, Nakamura N, Miyashita Y. Amygdalar enlargement associated with unique perception. Cortex. 2010;46(1):94-9. doi:10.1016/j.cortex.2008.08.001.

Binder JR, Desai RH. The neurobiology of semantic memory. Trends Cogn Sci. 2011;15(11):527-36. doi:10.1016/j.tics.2011.10.001.

Boccalandro ER. G-36: Teste não verbal de inteligência. São Paulo: Vetor; 2003.

Budson $A E$, Price $B H$. Memory dysfunction in neurological practice. Pract Neurol. 2007;7:42-7.

Campos RC. Além dos números há uma pessoa: Sobre a utilização clínica de testes. Avaliação Psicológica. 2013;12(3):291-8.

Carvalho LF, Primi R. Evidências de validade para o IDTP baseadas em variáveis externas. Avaliação Psicológica. 2013;12(3):387-95.

Cattell RB. Princípios de esquemas nos testes "projetivos" ou de má percepção da personalidade. In: Anderson HH, Anderson GL, editors. Técnicas projetivas do diagnóstico psicológico. São Paulo: Mestre Jou; 1951/1978. p. 69-111.

Cohen J. A power primer. Psychol Bull. 1992;112(1):155-9. doi:10.1037/ 0033-2909.112.1.155.

Crisi A. Manuale del test di Wartegg: Norme per la raccolta, la siglatura e I'interpretazione. Roma: Magi; 2007.

Ekman P. Emotions revealed. New York: Times Book; 2003.

Fensterseifer L, Werlang BSG. Apontamentos sobre o status científico das técnicas projetivas. In: Villemor-Amaral AE, Werlang BSG, editors. Atualizações em métodos projetivos para avaliação psicológica. São Paulo: Casa do Psicólogo; 2008. p. 15-33.

Frank LK. Projective methods for the study of personality. J Psychol. 1939:8(2):389-413. doi:10.1080/00223980.1939.9917671.

Freitas AMLF. Guia de aplicação e avaliação do teste de Wartegg. São Paulo: Casa do Psicólogo; 1993.

Freud S. Totem e tabu. In: Obras psicológicas completas de Sigmund Freud: Edição standard brasileira (Vol. 13, pp. 11-163). Rio de Janeiro: Imago; 1913/2006.

Freud S. Rascunho H: Paranoia. In: Obras psicológicas completas de Sigmund Freud: Edição standard brasileira (Vol. 1, pp. 253-258). Rio de Janeiro: Imago; 1950/2006.

Gabowitz D, Zucker M, Cook A. Neuropsychological assessment in clinical evaluation of children and adolescents with complex trauma. J Child Adolesc Trauma. 2008;1(2):163-78. doi:10.1080/19361520802003822. 
Joos AAB, Cabrillac E, Hartmann A, Wirsching M, Zeeck A. Emotional perception in eating disorders. Int J Eat Disord. 2009;42(4):318-25. doi:10.1002/eat.20621.

Kinget GM. The drawing-completion test: a projective technique for the investigation of personality, based on the Wartegg Test Blank. New York: Grune \& Stratton; 1952.

Koffka K. Princípios de psicologia da gestalt. São Paulo: Cultrix; 1935/1975.

Köhler W. Psicologia da gestalt. Belo Horizonte: Itatiaia; 1947/1968.

Lezak MD, Howieson DB, Loring DW. Neuropsychological assessment. 4th ed. New York: Oxford University Press; 2004.

Meyer GJ, Kurtz JE. Advancing personality assessment terminology: time to retire "objective" and "projective" as personality test descriptors. J Pers Assess. 2006;87(3):223-5. doi:10.1207/s15327752jpa8703_01.

Meyer GJ, Finn SE, Eyde LD, Kay GG, Moreland KL, Dies RR, et al. Psychologica testing and psychological assessment: a review of evidence and issues. Am Psychol. 2001:56(2):128-65. doi:10.1037/0003-066X.56.2.128.

Meyer GJ, Viglione DJ, Mihura JL, Erard RE, Erdberg P. Rorschach performance assessment system: administration, coding, interpretation, and technical manual. Toledo: Rorschach Performance Assessment System; 2011.

Miguel FK. Mitos e verdades no ensino de técnicas projetivas. Psico-USF. 2014;19(1):97-106. doi:10.1590/S1413-82712014000100010.

Miguel FK, Primi R. Estudo psicométrico do Teste Informatizado de Percepção de Emoções Primárias. Avaliação Psicológica. 2014:13(1):1-9.

Miguel FK, Finoto BAS, Miras BD. Percepção emocional e traços de personalidade: Estudo de validade divergente. Encontro: Revista de Psicologia. 2013a;16(24):107-20.

Miquel FK, Ogaki HA, Inaba CM, Ribeiro DO. Percepção emocional e inteligência: Contribuições para o modelo CHC. Revista Sul-Americana de Psicologia. 2013b;1 (1):36-47.

Mihura JL, Meyer GJ, Dumitrascu N, Bombel G. The validity of individual Rorschach variables: systematic reviews and meta-analyses of the comprehensive system Psychol Bull. 2013;139(3):548-605. doi:10.1037/a0029406.

Moritz S, Kempke S, Luyten P, Randjbar S, Jelinek L. Was Freud partly right on obsessive-compulsive disorder (OCD)? Investigation of latent aggression in OCD. Psychiatry Res. 2011;187:180-4. doi:10.1016/j.psychres.2010.09.007.

Niedenthal PM, Krauth-Gruber S, Ric F. Psychology of emotion: Interpersonal, experiential, and cognitive approaches. New York: Psychology Press; 2006.

Perry W, Potterat E, Auslander L, Kaplan E, Jeste D. A neuropsychological approach to the Rorschach in patients with dementia of the Alzheimer type. Assessment. 1996;3(3):351-63. doi:10.1177/1073191196003003014.

Peterson E, Miller S. The Eyes Test as a measure of individual differences: how much of the variance reflects verbal IQ? Front Psychol. 2012;3(220):1-6. doi:10.3389/fpsyg.2012.00220.

Plutchik R. Emotions and life: perspectives from psychology, biology and evolution. Washington: American Psychological Association; 2002.

Porcelli P, Giromini L, Parolin L, Pineda JA, Viglione DJ. Mirroring activity in the brain and movement determinant in the Rorschach test. J Pers Assess. 2013;95(5):444-56. doi:10.1080/00223891.2013.775136.

Primi R, Almeida LS. Bateria de Provas de Raciocínio (BPR-5): Manual técnico. São Paulo: Casa do Psicólogo; 2000.

Rutherford A. B. F. Skinner and the Auditory Inkblot: the rise and fall of the Verbal Summator as a projective technique. Hist Psychol. 2003;6(4):362-78. doi:10.1037/1093-4510.6.4.362.

Schneider WJ, McGrew KS. The Cattell-Horn-Carroll (CHC) model of intelligence. In: Flanagan DP, Harrison PL, editors. Contemporary intellectual assessment theories, tests, and issues. 3rd ed. New York: Guilford; 2012. p. 99-144.

Skinner BF. The Verbal Summator and a method for the study of latent speech. J Psychol. 1936;2(1):71-107. doi:10.1080/00223980.1936.9917445.

Skinner BF. Ciência e comportamento humano. São Paulo: Martins Fontes; 1953/2003.

Spreen O, Strauss E. A compendium of neuropsychological tests: Administration, norms, and commentary. 2nd ed. New York: Oxford University Press; 1998.

Strongman KT. The psychology of emotion: from everyday life to theory. Chichester: Wiley; 2003

Villemor-Amaral AE. As pirâmides coloridas de Pfister: Versão para crianças e adolescentes. São Paulo: Casa do Psicólogo; 2014.

Wechsler D. WISC IV - Escala Wechsler de inteligência para crianças: Manual técnico. São Paulo: Casa do Psicólogo; 2013.

\section{Submit your manuscript to a SpringerOpen ${ }^{\circ}$ journal and benefit from:}

- Convenient online submission

- Rigorous peer review

- Immediate publication on acceptance

- Open access: articles freely available online

- High visibility within the field

- Retaining the copyright to your article

Submit your next manuscript at $\gg$ springeropen.com 